\section{Scaling sorbent materials for real oil-sorbing applications and environmental disasters - ADDENDUM}

doi: https://doi.org/10.1557/mre.2019.3

The following footnote should be included in this article [1]:

This paper was commissioned and accepted for publication by David Ginley, who served as Editor-in-Chief of this journal from 2014-2018.
Andrew Patalano, Fabian Villalobos, Pedro Pena, Evan Jauregui, Cengiz Ozkan, and Mihri Ozkan

\section{REFERENCE:}

1. Patalano A., Villalobos F., Pena P., Jauregui E., Ozkan C., \& Ozkan M. (2019). Scaling sorbent materials for real oil-sorbing applications and environmental disasters. MRS Energy \& Sustainability, 6, E3. Cambridge University Press. 